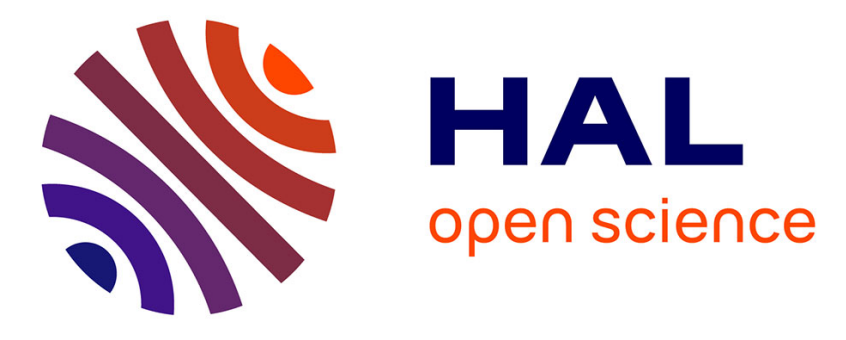

\title{
Grounded Colocated Antennas for Wideband Vector Sensor Applications
}

Johan Duplouy, Christophe Morlaas, Hervé Aubert, Patrick Potier, Philippe Pouliguen, Christopher Djoma

\section{To cite this version:}

Johan Duplouy, Christophe Morlaas, Hervé Aubert, Patrick Potier, Philippe Pouliguen, et al.. Grounded Colocated Antennas for Wideband Vector Sensor Applications. APS/URSI 2017, IEEE International Symposium on Antennas and Propagation and USNC-URSI Radio Science Meeting., Jul 2017, San Diego, United States. 2p., 10.1109/APUSNCURSINRSM.2017.8073030 . hal-01593455

\section{HAL Id: hal-01593455 \\ https://hal-enac.archives-ouvertes.fr/hal-01593455}

Submitted on 26 Sep 2017

HAL is a multi-disciplinary open access archive for the deposit and dissemination of scientific research documents, whether they are published or not. The documents may come from teaching and research institutions in France or abroad, or from public or private research centers.
L'archive ouverte pluridisciplinaire HAL, est destinée au dépôt et à la diffusion de documents scientifiques de niveau recherche, publiés ou non, émanant des établissements d'enseignement et de recherche français ou étrangers, des laboratoires publics ou privés. 


\title{
Grounded Colocated Antennas for Wideband Vector Sensor Applications
}

\author{
J. Duplouy*, C. Morlaas*, H. Aubert ${ }^{\dagger}$, P. Potier ${ }^{\ddagger}$, P. Pouliguen ${ }^{\S}$ and C. Djoma ${ }^{\S}$ \\ *TELECOM-EMA, ENAC, F-31055 Toulouse, France, Email: johan.duplouy@enac.fr \\ ${ }^{\dagger}$ LAAS-CNRS, Université de Toulouse, CNRS, INTP, F-31400 Toulouse, France \\ $\ddagger$ DGA, F-35170 Bruz, France \\ ${ }^{\S}$ DGA, F-75509 Paris, France
}

\begin{abstract}
In this communication, a wideband vector sensor for embedded applications is proposed. This original sensor is composed of two orthogonal and colocated semi-circular arrays of Vivaldi antennas mounted over a ground plane. Stable radiation patterns of two wideband magnetic dipoles and one wideband electric dipole are obtained from full-wave electromagnetic simulations over a 1.69:1 impedance bandwidth with an original control of the excitation.
\end{abstract}

\section{INTRODUCTION}

A standard technique for estimating the Direction of Arrival (DoA) of an incoming electromagnetic signal consists to exploit the ability of a vector sensor with polarization diversity to measure the six components of the electromagnetic field [1]. An ideal vector sensor is composed of six orthogonal and colocated antennas, three electric dipoles and three magnetic dipoles. A few solutions covering the 3D space have recently emerged. One active solution for frequencies below $30 \mathrm{MHz}$ was reported in [2]. Based on [3], a dual-band vector sensor for embedded applications was reported using dual-band radiating elements [4].

Recently, many wideband electric dipoles have been proposed and could be advantageously used in a wideband vector sensor. Unfortunately, very few research works focus on wideband magnetic dipoles. A well-known approach for designing a magnetic dipole is to generate a uniform current distribution on a small electric loop antenna [5]. However, such design suffers from its naturally large input reactance and thereby makes impedance matching difficult. A magnetic dipole with a 1.52:1 bandwidth consisting of four pairs of flag shaped dipoles with parasitic strips printed on a substrate in a clockwise manner was reported in [6]. A circular array of eight tapered slot elements which provides a $\pm 2 \mathrm{~dB}$ omnidirectionality in the E-plane within the long term evolution band (1.9-2.7 GHz) was proposed in [7].

A wideband vector sensor mounted over a ground plane for embedded applications is reported here. This novel sensor presents not only a wide impedance bandwidth (1.69:1) but also exhibits stable radiation patterns over the bandwidth. The proposed feeding network allows using only two orthogonal and colocated semi-circular arrays of Vivaldi antennas to obtain the radiation patterns of two magnetic dipoles and one electric dipole in the upper half-space. To the best author's knowledge, no previous development on designing a passive vector sensor that can be used for wideband 3D direction finding have been reported.

\section{VECTOR SENSOR AND FEEDING STRUCTURES}

A grounded vector sensor may consist of three orthogonal and colocated antennas, two magnetic dipoles and one electric dipole, measuring the components $H_{x}, H_{y}$ and $E_{z}$ of the magnetic and electric incident fields in the Cartesian coordinate system (depicted in Fig. 2(b)), respectively.

\section{A. Design strategy used for the wideband magnetic dipole}

A circular electric field over a large frequency range can be achieved by using a circular array of Vivaldi antennas. This configuration allows achieving radiation patterns of a wideband magnetic dipole. The geometry of the magnetic dipole and its feeding circuit are shown in Fig. 1(a) and Fig. 1(b), respectively. The radiating section consists of a semicircular array of four Vivaldi antennas mounted over an infinite ground plane. This configuration is close to the one reported in [7] but the excitation differs significantly. As a matter of fact the proposed two-port feeding network allows to cross and colocate two semi-circular arrays of Vivaldi antennas. According to the geometry of this two-port feeding network, a $180^{\circ}$ phase shift must be designed in order to create a circularly-polarized electric field in the plane of the array and to shape the required radiation pattern of the magnetic dipole. The underlying design principle is illustrated in Fig. 1(a). According to the image theory, the radiation pattern in the upper half-space of this grounded antenna is equivalent to the one of a circular array of eight Vivaldi antennas. Furthermore, this antenna can be easily mounted on a metallic support for embedded applications.

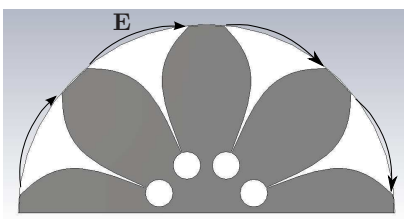

(a)

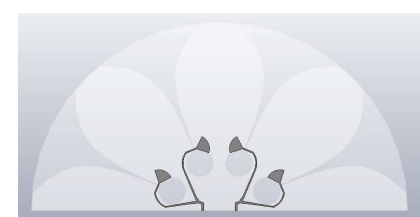

(b)
Fig. 1. Topology of the wideband magnetic dipole. (a) Front view (b) Back view 


\section{B. Design strategy used for the wideband electric dipole}

The radiation pattern of an electric dipole can be synthesized using two orthogonal and colocated semi-circular arrays of Vivaldi antennas when each port are fed in phase.

\section{Proposed configuration for the wideband vector sensor}

Fig. 2 presents the vector sensor topology investigated in this communication. Excitation ports feed two magnetic dipoles and one electric dipole as specified in Table I. The reference impedance at each port is $50 \Omega$. The antenna is included in a half-sphere of radius $0.57 \lambda_{0}$, where $\lambda_{0}$ is the free space wavelength at the lowest operating frequency.

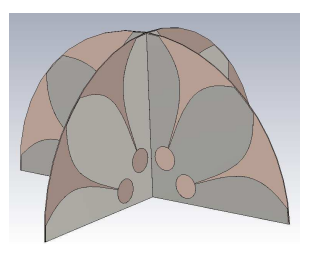

(a)

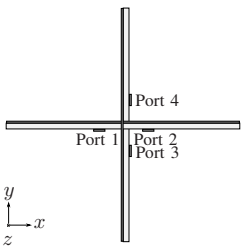

(b)
Fig. 2. Topology of the vector sensor. (a) 3D view (b) Top view

TABLE I

AMPLITUDE AND PHASE AT ALL EXCITATION PORTS

\begin{tabular}{|c|c|c|c|c|}
\hline Mode & Port 1 & Port 2 & Port 3 & Port 4 \\
\hline Magnetic dipole $H_{x}$ & 1 & $1 \angle 180^{\circ}$ & 0 & 0 \\
\hline Magnetic dipole $H_{y}$ & 0 & 0 & 1 & $1 \angle 180^{\circ}$ \\
\hline Electric dipole $E_{z}$ & 1 & 1 & 1 & 1 \\
\hline
\end{tabular}

\section{Simulated performances}

Electromagnetic simulations have been performed using a full-wave software. The investigated antenna exhibits a 1.69:1 impedance bandwidth $(\Gamma \leqslant-10 \mathrm{~dB})$ from $1.14 \mathrm{GHz}$ up to $1.93 \mathrm{GHz}$. The simulated radiation patterns for the magnetic dipole $H_{x}$ and the electric dipole $E_{z}$ of the investigated vector sensor are plotted at several frequencies in the bandwidth in Fig. 3(a) and Fig. 3(b), respectively. The electromagnetic simulation results confirm that stable radiation patterns of two magnetic dipoles and one electric monopole can be achieved over a wide bandwidth from the proposed control of the excitation ports. As it can be observed in Fig. 3(a), the radiation pattern of the magnetic dipole $H_{x}$ is quasi-omnidirectional with some ripples lowers than $2 \mathrm{~dB}$ in the E-plane. In Fig. 3(b), the radiation pattern of the electric dipole $E_{z}$ gives undesirable ripples in the $\mathrm{H}$-plane at frequencies higher than $1.8 \mathrm{GHz}$. Consequently, the simulated characteristics make the proposed vector sensor a good candidate for wideband 3D DoA estimation.

\section{CONCLUSION}

A passive vector sensor for wideband 3D DoA estimation has been proposed in this communication. An appropriate control of the excitation ports of two orthogonal and colocated

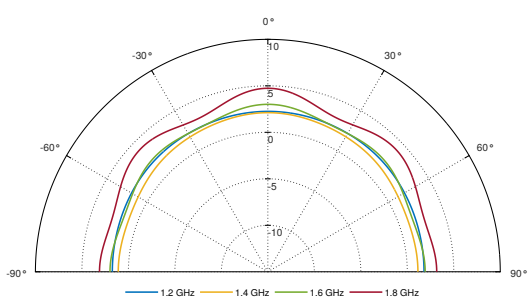

(a)

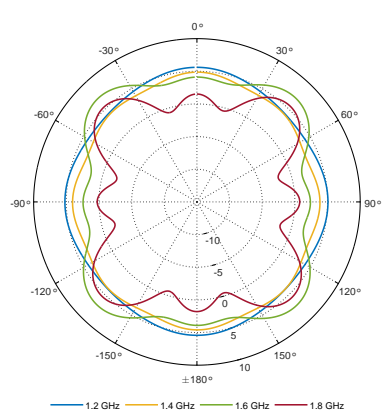

(b)

Fig. 3. Simulated radiation patterns in the (a) E-plane of the magnetic dipole $H_{x}$ and (b) H-plane of electric dipole $E_{z}$ at different frequencies

arrays of Vivaldi antennas enables to shape stable radiation patterns of two magnetic dipoles and one electric dipole over a 1.69:1 impedance bandwidth. This sensor is included in a half-sphere within a $0.57 \lambda_{0}$ radius, where $\lambda_{0}$ is the free space wavelength at the lowest operating frequency. Miniaturization techniques will be explored in future studies to reduce the size of the proposed vector sensor.

\section{ACKNOWLEDGEMENT}

The authors would like to thank the French Defense Agency (Direction Général de l'Armement, DGA) and the Occitanie regional council for their financial support.

\section{REFERENCES}

[1] A. Nehorai and E. Paldi, "Vector-sensor array processing for electromagnetic source localization," IEEE Transactions on Signal Processing, vol. 42, no. 2, pp. 376-398, Feb 1994.

[2] B. Almog, "Compact 3D direction finder," Patent, Mar, 2013, EP20120184835.

[3] J. Lominé, C. Morlaas, and H. Aubert, "Novel vector sensors design with three co-located or distributed elements for the 3D DOA estimation," Progress In Electromagnetics Research B, vol. 57, pp. 207-220, 2014.

[4] J. Lominé, C. Morlaas, C. Imbert, and H. Aubert, "Dual-band vector sensor for direction of arrival estimation of incoming electromagnetic waves," IEEE Transactions on Antennas and Propagation, vol. 63, no. 8, pp. 3662-3671, Aug 2015.

[5] W. Stutzman and G. Thiele, Antenna Theory and Design, 3rd ed. Wiley, 2012.

[6] Y. Yu, F. Jolani, and Z. Chen, "A wideband omnidirectional horizontally polarized antenna for 4G LTE applications," IEEE Antennas and Wireless Propagation Letters, vol. 12, pp. 686-689, 2013

[7] T. S. P. See, X. Qing, and Z. N. Chen, "A wideband horizontally polarized omnidirectional antenna," in IEEE 4th Asia-Pacific Conference on Antennas and Propagation, June 2015, pp. 294-295. 